\title{
Escola, formação humana e a contribuição pedagógica de Dermeual Saviani no cenário contemporâneo
}

\author{
School, human formation and the pedagogical contribution of \\ Dermeval Saviani in the contemporary scenario
}

\section{Escuela, formación humana y la contribución pedagógica de Dermeval Saviani en el escenario contemporâneo}

\author{
João Francisco Lopes de Lima' \\ Universidade do Porto, Faculdade de Psicologia e de Ciências da Educação, Investigador \\ Doutorado \\ http://lattes.cnpq.br/6995362925512176 \\ http://orcid.org/0000-0002-0188-2354
}

Resumo: 0 presente estudo analisa o pensamento pedagógico de Dermeval Saviani acerca das relações entre escola, formação humana e democracia, considerando o seu embasamento filosófico, as implicações pedagógicas e a possibilidade de diálogo de sua teoria pedagógica com o cenário educacional contemporâneo, marcado pelas características do pós-moderno. 0 estudo, de caráter bibliográfico, tomou como material de análise os textos do autor que tratam sobre a teoria pedagógica de modo direto e outros que trazem o tema ou seus elementos de modo indireto e que possibilitaram esclarecer questões postas no curso da reflexão. Este artigo percorre um breve histórico sobre o autor, sobre o contexto que gerou a sua teoria pedagógica, aponta a influência filosófica de Marx e de Gramsci, verifica como o autor dialoga com seus críticos e como se posiciona diante da evidência da crise do modelo socialista e da emergência do pós-moderno no cenário contemporâneo. Por fim, reconhecendo a pluralidade epistemológica e social do cenário pós-moderno, considera a possível contribuição da pedagogia histórico-crítica para a educação contemporânea.

Palavras-chave: Discurso pedagógico. Pós-moderno. Democracia. Pedagogia histórico-crítica. Saviani.

Abstract: The present study analyses the pedagogical thinking of Dermeval Saviani on the relations between school, human formation and democracy, considering its philosophical background, the pedagogical implications and the possibility of a dialogue between his pedagogical theory and the contemporary educational scenario, shaped by characteristics of the post-modern. The study, of bibliographic character, was done with the direct analyses of the author's texts about pedagogical theory but also others that bring about the theme in a more indirect way and that made possible to

Doutor em Educação pela Universidade Federal Fluminense; Pós-Doutor em Ciências da Educação pela Universidade do Porto. 
clarify questions raised in the course of reflection. This article deals with a brief history of the author highlighting the context that gave origin to his pedagogical theory; points out Marx and Gramsci's philosophical influence; verifies how the author dialogues with its critics and how he positions himself before the evidence of the crisis of the socialist model and of the emergency of the postmodern in the contemporary scenario. Finally, recognizing the epistemological and social plurality of the postmodern scenario, the study considers the possible contribution of the historical-critical pedagogy to contemporary education.

Keywords: Pedagogic discourse. Post-modern. Democracy. Historical-critical pedagogy. Saviani.

Resumen: El presente estudio analiza el pensamiento pedagógico de Dermeval Saviani acerca de las relaciones entre escuela, formación humana y democracia, considerando su base filosófica, las implicaciones pedagógicas y la posibilidad de diálogo de su teoría pedagógica con el escenario educativo contemporáneo, marcado por las características del posmoderno. El estudio, de carácter bibliográfico, tomó como material de análisis los textos del autor que tratan sobre la teoría pedagógica de modo directo y otros que traen el tema o sus elementos de modo indirecto y que permitieron aclarar cuestiones planteadas en el curso de la reflexión. Este artículo presenta una breve biografía sobre el autor, sobre el contexto que generó su teoría pedagógica, apunta la influencia filosófica de Marx y de Gramsci, verifica cómo el autor dialoga con sus críticos y cómo se posiciona ante la evidencia de la crisis del modelo socialista y de la emergencia del posmoderno en el escenario contemporáneo. Por último, reconociendo la pluralidad epistemológica y social del escenario posmoderno, considera su posible contribución de la pedagogía histórico-crítica para la educación contemporánea.

Palavras clave: Discurso pedagógico. Posmoderno. Democracia. Pedagogía histórico-crítica. Saviani.

Recebido em 24 de novembro de 2018

Aceito em 24 de maio de 2019 Publicado em 05 de julho de 2019

\section{DERMEUAL SAUIANI E A PRETENSÃO DE EDUCAR PARA A DEMOCRACIA}

Faz parte da tradição da escola moderna a transformação dos sujeitos, por meio da educação, de súditos em cidadãos. E o povo, para se transformar de súdito em cidadão, precisa ser educado. Nesse sentido, ressalta-se o papel da escola pública, com oferta universal, de caráter obrigatório, gratuita e laica. É justamente a partir desse "significado histórico" da escola (SAVIANI, 2018a) como projeto de formação que Dermeval Saviani refletiu, pesquisou e produziu ao longo de sua trajetória como intelectual da educação, tendo como compromisso um modelo de educação "tributária da concepção dialética." (SAVIANl, 2008, p. 24). 
Esse modelo pedagógico ficou conhecido como Pedagogia Histórico-Crítica, conforme foi nomeado em 1984, e configurou uma marca fundamental na vasta obra desse professor. Saviani (2017b, p. 654) entende que a escola é o instrumento privilegiado de "construção da ordem democrática" e que a "escola democrática" se relaciona intrinsecamente com a ideia da cidadania", por ele entendida para além da "democracia formal" das sociedades liberais que oferece a noção de igualdade jurílica sem alterar, necessariamente, a complexa dinâmica socioeconômica do mundo. A democracia real possibilitaria a verdadeira emancipação humana e esta seria atingida somente no modelo de sociedade socialista, situação em que haveria, segundo ele destaca, baseado em Marx, que o livre desenvolvimento de cada um é condição para o livre desenvolvimento de todos (SAVIANI, 2017b, p. 656).

Ao longo da sua trajetória como professor e como pesquisador, além de produzir e desenvolver o lastro da teoria pedagógica que defende, Saviani, atuou de forma propositiva em inúmeras questões da política educacional do País. Gaudêncio Frigotto ${ }^{2}$ destaca-o como sendo, "sem dúvida, o filósofo e intelectual marxista mais importante do campo educacional no Brasil." (FRIG0TTO, 2017, p. 509).

0 presente estudo ${ }^{3}$ focaliza no pensamento pedagógico de Dermeval Saviani $i^{4}$ acerca das relações entre escola, formação humana e democracia, considerando o seu embasamento filosófico, as implicações pedagógicas e a sua possibilidade de diálogo com o cenário educacional contemporâneo, marcado pelas características do pós-moderno. Para este estudo, de caráter bibliográfico, foram selecionados para análise os textos que tratam sobre a teoria pedagógica de modo direto e outros que trazem o tema ou seus elementos de modo indireto e que serviram para esclarecer questões postas no curso da reflexão. 0 artigo percorre um breve histórico sobre $\circ$ autor, sobre $\circ$ contexto que gerou a sua teoria pedagógica, as suas influências filosóficas, principalmente oriundas de Marx e de Gramsci, verifica como o autor dialoga com seus críticos e, ainda, como se posiciona diante da evidência da crise do modelo socialista e da emergência do pós-moderno no cenário contemporâneo. Por fim, reconhecendo a pluralidade epistemológica e social do cenário pós-moderno, considera a possível contribuição da Pedagogia Histórico-Critica para a educação contemporânea.

2 Gaudêncio Frigotto é Professor e Pesquisador na Universidade do Estado do Rio de Janeiro. Saviani foi seu orientador de Doutorado (concluído na PUCSP, em 1983).

3 Uma versão reduzida deste trabalho foi apresentada no VI Seminário da Educação Brasileira, promovido pelo Centro de Estudos Educação e Sociedade (CEDES) e realizado na Universidade Estadual de Campinas (Unicamp), de 10 a $१ 2$ de dezembro de 2018.

4 Esse estudo serve-se de uma discussão inicial sobre a contribuição de Saviani para a ideia de educar para a democracia por meio da escola no Brasil do século XX, desenvolvida em um dos capítulos da minha tese de doutoramento (LIMA, 2009). 


\section{O AUTOR, O CONTEXTO DE PRODUÇÃO DE SUA OBRA ESCOLA E DEMOCRACIA E OS FUNDAMENTOS GERAIS DO SEU MODO DE PENSAR A EDUCAÇÃO}

Dermeval Saviani nasceu em 1944 em Santo Antônio da Posse, no Estado de São Paulo, distante pouco mais de 140 quilômetros da capital. Veio de uma família de origem italiana que migrou para a capital paulista em 1948. A maior parte da sua formação básica ocorreu em escolas católicas para a formação religiosa de futuros sacerdotes, nas quais permaneceu até 1963. Ao sair do Seminário, nesse mesmo ano, seguiu o Curso de Filosofia na Pontifícia Universidade Católica de São Paulo (PUCSP), onde graduou-se em 1966. Doutorou-se em Filosofia da Educação pela mesma Universidade, em 1971 (AKSENEN, 2015).

Iniciou como professor universitário em 1967, quando tinha apenas 23 anos, na PUCSP. Em 1980, passou a atuar na Universidade Estadual de Campinas (Unicamp), onde tem o status de Professor Emérito. É, também, Pesquisador Emérito do Conselho Nacional de Desenvolvimento Científico e Tecnológico (CNPQ).

No Currículo Lattes de Saviani, ${ }^{5}$ com dados apurados em 3 de outubro de 2018, constam expressivos indicadores da sua vida acadêmica. São mais de 140 artigos. São 29 livros e 76 capítulos de livros, alguns deles com várias edições. Nesse mapeamento, feito a partir do que informa o currículo do autor disponível na Plataforma Lattes, verifica-se que os seus escritos se distribuem, não de forma estanque, em quatro grandes campos: estrutura e política educacional; filosofia da educação; história da educação e teoria pedagógica. ${ }^{6}$

Estão concluídas 36 orientações de Mestrado (entre 1974 e 2000), 58 orientações de Doutorado (entre 1978 e 2013) e 22 supervisões de Pós-Doutorado (entre 1992 e 2017). Destaque-se que nomes notáveis da Educação Brasileira estiveram sob a sua orientação em seus doutoramentos, como Naura Ferreira, José Carlos Libâneo, Guacira Lopes Louro, Osmar Fávero, Acácia Kuenzer, Gaudêncio Frigotto e Guiomar Namo de Mello, entre outros.

Sua produção acadêmica inicial teve como objetivo gerar material para as suas aulas de Filosofia da Educação ministradas na PUCSP. Esses materiais foram reunidos e, mais tarde, transformados em artigos e livros. A obra Escola e Democracia, que em 2018 atingiu a $43^{a}$ edição, foi publicada pela Editora Autores Associados em setembro de 1983. Representa, pois, "um marco do processo de formulação da Pedagogia Histórico-Crítica" (SAVIANI, 2014, p. 721) e tornou-se referência na sua trajetória acadêmica e intelectual.

0 currículo lattes de Dermeval Saviani está disponível no link: http://lattes.cnpq.br/2205251281123354.

Utilizo e reafirmo aqui o enquadramento apontado por Gama e Santos Júnior (2016) sobre a obra do autor. 
Escola e Democracia começou a ganhar forma nas "discussões travadas na primeira turma de doutorado em Educação da PUC-SP.” (SAVIANl, 2008, p. 23). Em 1979, sob a sua coordenação, "a primeira turma de doutorado da PUC-SP lança-se ao desafio de construir uma abordagem dialética do fenômeno educativo." (DOZOL, 1994, p. 105-106). Saviani relata que, na década de 1980, no Brasil, ainda sob o comando dos Governos Militares (1964-1985), havia a "necessidade de construir uma pedagogia contra-hegemônica, isto é, que em lugar de servir aos interesses dominantes, se articulasse com os interesses dominados." (SAVIANI, 2008, p. 18).

Escola e Democracia ganhou a forma de livro com a reunião de quatro textos escritos entre 1981 e 1983, três deles publicados antes como artigos independentes. A obra contém uma crítica ao que Saviani considerava os dois modelos fundamentais de educação existentes no Brasil à época de seu lançamento: o modelo tradicional e o modelo escolanovista. Havia, ainda, a influência tecnicista, de certo modo derivada da visão escolanovista, resultado da Reforma do Ensino promovida pelos Governos Militares, em 1971.0 seu pressuposto era o de que a Escola Nova e seu ideário tinham se tornado hegemônicas e haviam "ganhado a cabeça dos professores." (SAVIANI, 2012, p. 80).

A Reforma de 1971, instituída a partir da Lei n. 5.692/71, havia promovido o recrudescimento da formação propedêutica, enfraquecido o lastro curricular reflexivo e cedido espaço para a formação técnica para gerar mão de obra qualificada para a indústria em crescimento no País. Talvez, isso explique um pouco mais claramente o apelo de Saviani por uma pedagogia que resgatasse a importância dos conteúdos ao defender uma pedagogia capaz de "recuperar o papel da escola como instrumento de acesso ao saber elaborado." (SAVIANI, 2014, p. 29). Ele complementa essa ideia, apontando que, para as formas não elaboradas, cotidianas e espontâneas, o povo não precisa da escola.

Saviani (2008, p. 24), diante da necessidade de construir uma "pedagogia contrahegemônica," buscou formular uma "teoria crítica não reprodutivista", "tributária da concepção dialética", inspirada de modo especial em Marx, Engels e Gramsci e nas bases da Psicologia Histórico-Cultural de Vygotsky. Esse embasamento, diz o autor, permitiria a "apreensão da concepção de fundo (de ordem ontológica, epistemológica e metodológica) que caracteriza o materialismo histórico." (SAVIANI, 2017b, p. 715).

Saviani $(2008,2014,2018 \mathrm{~b})$ esclarece que toda teoria pedagógica é uma teoria também da educação, mas nem toda teoria da educação é, necessariamente, uma teoria pedagógica, pois esta se organiza para dar suporte à prática educativa, para orientar a ação em torno dos processos de ensino e de aprendizagem. Segundo ele, as teorias pedagógicas possuem um caráter pragmático e programático e carregam uma concepção política de educação. Podem servir aos interesses da burguesia capitalista e aos interesses dominantes no sentido de "hegemonizar o campo educativo" ou podem estar a serviço da 
classe trabalhadora e servir aos interesses dos dominados com vistas a "transformar a ordem vigente" (SAVIANI, 2008, p. १1).

Saviani (2017a) relata algumas etapas da construção do seu pensamento e dos seus posicionamentos, destacando, em primeiro lugar, a influência da fenomenologia, ainda nas aulas da Graduação. Ao realizar o doutorado, buscou integrar a fenomenologia e a dialética, inicialmente, denominado como "método fenomenológico-dialético". Lendo Marx, relata que entendeu que a compreensão dialética vai da síncrese (visão caótica) e chega à síntese (totalidade feita de relações numerosas e complexas), passando pela análise (abstrações) e, com isso, concluiu que a expressão "método dialético" era suficiente, sem a necessidade de um "prefixo".

Saviani (2017a, p. 715) buscou nos "autores marxistas sobre educação"7 e nas "experiências dos países socialistas" ${ }^{8}$ os elementos que apontassem na direção de uma "teoria histórico-dialética da educação." Ele pondera que "nas matrizes do materialismo histórico não encontramos uma teoria sistematizada da educação" e, sim, possibilidades, "derivações de sentido". Alerta que "não é suficiente perscrutar as implicações educacionais do conjunto da obra dos fundadores do materialismo histórico." (SAVIANI, 2017a, p. 715). 0 que esse diálogo interpretativo com "os mestres do marxismo" pode nos indicar, aponta Saviani, "não é [a] solução do problema leducacional] em si, mas o método de sua construção." (SAVIANI, 2017a, p. 720, grifo nosso).

Em 1991, o autor publicou o livro Pedagogia histórico-crítica: primeiras aproximações, pela Editora Autores Associados e, na obra, procura descrever as etapas práticas da sua teoria pedagógica. A raiz moderna de seu pensamento pedagógico encontra-se expressa em destaque na contracapa da $8^{a}$ edição: "para a pedagogia histórico-crítica, educação é o ato de produzir, direta e intencionalmente, em cada indivíduo singular, a humanidade que é produzida histórica e coletivamente pelo conjunto dos homens." (SAVIANI, 2003b).

\section{A EDUCAÇÃO ESCOLAR E AS TEORIAS EDUCACIONAIS - A CRÍTICA SOCIOLÓGICA}

Para Saviani (2002, 2003a, 2012, 2018a), as teorias educacionais dividem-se entre dois grandes fins para a educação. Em um grupo estariam as que entendem a educação

7 Saviani inspirou-se em nomes que refletiram sobre a educação na perspectiva marxista, como Moisey Pistrak (1888-1937, educador russo), Anton Makarenko (1888-1939, educador russo), Mario Manacorda (1914-2013, educador italiano), Giusepe Radice (1879-1938, educador italiano), Georges Snyders (1917-2011, educador francês) e Bogdan Suchodolski (1903-1992, educador polonês).

8 Saviani analisou as experiências de países como a União das Repúblicas Socialistas Soviéticas (URSS), China, Cuba e Alemanha Oriental. 
escolar como um instrumento de equalização das diferenças sociais e, portanto, são promotoras do ajuste social. Nesse caso, a formação escolar minimizaria as desvantagens que o sujeito pudesse ter por conta da sua origem e funcionaria como uma alavanca social ao fornecer-lhe a apropriação dos elementos da cultura.

A educação forneceria os elementos que sustentariam a promessa moderna de ascensão social por intermédio da escola. Para ele, essas teorias enxergariam a educação como um processo exógeno à vida social e relativizariam a força das contradições sociais e das desigualdades próprias de uma sociedade de classes. Noutro grupo estariam as teorias que entendem que a educação desenvolvida na escola é um fator de discriminação social, potencializadora da marginalidade e reforçadora da relação de dominação que existe entre as classes. Nessa perspectiva, haveria um entrelaçamento entre educação e situação social que acabaria reforçando a exclusão uma vez que o processo educacional não pode ser desenvolvido sem a interferência das variáveis sociais.

Essas duas frentes teóricas, sintetiza Saviani, no livro Escola e Democracia, representariam dois grandes grupos: as teorias não críticas e as teorias críticas reprodutivistas. As teorias não críticas indicariam uma pretensão equalizadora das diferenças sociais por meio da escola e vislumbrariam a possibilidade da escola de produzir uma nova realidade social a partir do trabalho que realiza, de modo independente das condições socioeconômicas em que se encontram inseridos os sujeitos. As teorias críticas, por sua vez, se de um lado reconheceriam a intersecção das condições sociais e educacionais e não considerariam possível compreender a educação senão a partir de seus condicionantes sociais (SAVIANI, 2003a, p. 16), sinalizariam que a educação cumpre mal a sua pretensa função emancipatória, cumprindo de fato a função de reprodução das relações de produção capitalistas.

Para Saviani (SAVIANI, 2003a, p. 31), as teorias não críticas, em que ele situa tanto a Escola Tradicional quanto a Escola Nova, são ingênuas ao tentarem realizar a promoção social por intermédio do trabalho da escola. As teorias críticas, por sua vez, prendem-se na interpretação dos motivos que explicam essa falta de êxito da escola e também não conseguem a superação do problema.

0 autor diz que o seu propósito é "retomar vigorosamente a luta contra a seletividade, a discriminação e o rebaixamento do ensino das camadas populares" (SAVIANI, 2003a, p. 31) e, para isso, pretende refletir sobre uma teoria da educação capaz de ir além da identificação das contradições do sistema escolar e da identificação das condições que resultam no fracasso dos alunos menos favorecidos em termos socioeconômicos, promovendo as condições práticas de sua superação por meio da escola. 


\section{A EDUCAÇÃO ESCOLAR E AS TEORIAS EDUCACIONAIS - A CRÍTICA FILOSÓFICA}

Quando Dermeval Saviani transita da crítica sociológica da educação e das suas dimensões conservadoras e reprodutivistas para uma leitura filosófica, situa a tradição educacional demarcada entre a pedagogia da essência e a pedagogia da existência, ${ }^{9}$ procede a justificação do conhecimento como fator de emancipação individual e o coloca na posição de centralidade para o processo pedagógico.

Nesse sentido, Saviani (2003a, p. 36) afirma duas teses básicas: o método tradicional possui caráter científico e, por estar focado no valor do conhecimento, possui caráter revolucionário, e a esse contexto corresponde uma "pedagogia da essência". Os métodos novos possuem caráter pseudocientífico e, por secundarizarem o valor do conhecimento e a preocupação com a transformação política, possuem caráter reacionário. A esse contexto corresponde uma "pedagogia da existência".

Dermeval Saviani atribuiu um caráter conservador à Escola Nova também por acreditar que esta tem pouco compromisso com a transformação política e com a superação da ordem econômico-social e, também, por colocar a ênfase nos meios de aprender em detrimento dos conteúdos culturais, o que ele considera um bem universal e um recurso emancipatório.

Os métodos novos, ao preferirem os meios de aprender, focam-se nos aspectos psicológicos, ou seja, nas motivações e interesses e acabam por "dissolver a diferença entre pesquisa e ensino" (SAVIANI, 2003a, p. 36), ao defenderem a reconstrução dos processos científicos. Para Saviani, essa diferença precisa ser estabelecida e, por isso, ele atribui o caráter científico à escola tradicional e pseudocientífico à Escola Nova, que se centra nos métodos, mas perde o conteúdo sistematizado e afrouxa a disciplina na tentativa de atender às motivações subjetivas.

Nessa direção, tomou o alvo prioritário das críticas à Escola Tradicional a ênfase no conteúdo e o transformou em mote para sustentar o que chamará de pedagogia revolucionária. Tomado pela influência gramsciana, entende que "o dominado não se liberta se não vier a dominar aquilo que os dominantes dominam." (SAVIANI, 2003a, p. 55). Assim, entende que a apropriação do capital cultural legado pela humanidade é uma ferramenta emancipatória a ser adquirida pelas classes populares. 0 domínio da cultura, expresso no 
acesso das camadas populares ao conhecimento já acessado pela burguesia, é visto como indispensável recurso para a participação política das massas.

Para Saviani (2018b), "o fio condutor" que atravessa o livro Escola e Democracia é precisamente a relação entre "escola e política", o que decorre de outra indissociabilidade que é a relação entre "política e educação". Em sua pedagogia, embora a educação e a política sejam inseparáveis, não são processos idênticos. Para Saviani (2003a, p. 72), nesse sentido, as práticas educativas supõem uma "heterogeneidade real", mas que devem convergir em direção a uma "homogenenidade possível" como ponto de chegada e objetivo pedagógico. Essa desigualdade real, expressa em uma visão caótica do todo, representa um tipo de totalidade que é a síncrese.

0 professor e o aluno possuem níveis diferentes de compreensão dessa realidade de partida. 0 professor, pelo seu conhecimento e experiência, iniciará o processo com uma visão sintética da prática social, já com algum nível de reflexão. Os alunos, por sua vez, possuem uma síntese precária e participarão do processo com a visão marcada pelas vivências empíricas, o que corresponde à visão sincrética, portanto, ainda superficial, não reflexiva.

0 objetivo final é tanto reduzir a precariedade da síntese do professor quanto a elevação dos alunos a um nível qualitativo superior. Eles poderão desenvolver uma capacidade de análise superior, como catarse, ao que tinham anteriormente em relação a uma dada prática social (SAVIANI, 2003a, 2015). Dermeval Saviani utiliza a noção de catarse no sentido gramsciano, que a traduz como elaboração e incorporação superior e consciente dos instrumentos culturais, que transforma a compreensão da estrutura em superestrutura e elemento ativo de transformação social. 0 processo pedagógico deverá conduzir os alunos e seus professores a uma nova totalidade, que contenha relações numerosas e mais complexas pela mediação da análise.

Para Saviani, a união indissociável entre trabalho produtivo e formação intelectual é coerente com a leitura marxista da sociedade e estaria melhor desenhada no conceito de politecnia, que "implica a união entre escola e trabalho ou, mais especificamente, entre instrução intelectual e trabalho produtivo." (SAVIANI, 2007c, p. 162). Para sustentar essa premissa, Saviani novamente busca apoio em Gramsci, que diz que o princípio educativo imanente à escola elementar é o conceito de trabalho (GRAMSCI, 1985, p. 130).

A filiação de Saviani ao pensamento gramsciano está assentada em duas questões básicas: a ideia de que educação e trabalho implicam uma unidade no processo educativo e a perspectiva de que cabe à escola, pela via da intelectualização que abastece a formação das consciências, erigir os novos dirigentes. Portanto, cabe a ela a formação de uma camada de intelectuais que dê homogeneidade e consciência da própria função na organização social. 
Esses "prepostos" do sistema, os intelectuais orgânicos, podem estar a serviço da ordem dominante ou servir de alavanca para a transformação social. 0 intelectual orgânico, na perspectiva de Gramsci, quando emerge das classes subalternas, traz consigo uma prática social esclarecida e elevada ao nível da consciência crítica, condições que permitem a liderança necessária à renovação do movimento histórico. Segundo a apreciação de Del Roio (2007, p. 71), essa ideia adquire peculiaridade, "porque [os intelectuais orgânicos estão] emersos do seio da própria classe e porque atuam historicamente em razão dos interesses da classe da qual se originaram."

Para esse tipo de intelectual, caberia forjar a coesão social, na dimensão da sociedade civil, para que a classe a que estão vinculados possa emergir e adquirir o domínio do poder público e, assim, reorganizar a ordem simbólica na dimensão da sociedade política. Para isso, Gramsci defendia o que chamou de "escola única", ou seja, uma escola humanista, de formação geral que desenvolvesse de forma equilibrada o trabalho técnico e o trabalho intelectual. Saviani (2007c) aponta que essa unidade representaria um elemento "ontológicohistórico" que traduz a unidade fundamental do sistema de ensino em que o trabalho funciona como princípio educativo.

Semeraro (2006) analisou a viabilidade do conceito de intelectual orgânico, como o formulou Gramsci, no complexo cenário pós-moderno. Semeraro reafirmou a unidade entre ciência e política e apontou que o cenário pós-moderno introduziu uma esterilização progressiva das possibilidades revolucionárias da organização da sociedade civil, mas não as impede. Saviani (2010), por sua vez, aponta que aderir ao pós-moderno significa abrir mão da ideia de "educação como formação e transmissão de modelos de vida voltados para a emancipação humana", resguardando que "a análise crítica e o debate das posições são um elemento integrante da tradição marxista." (SAVIANI, 2011a).

Marx (2008) apontou que, no sistema capitalista, o modo de produção da vida material condiciona o processo de vida social e política. Se a produção da vida humana sempre foi uma produção social, ela é marcada pelas condições materiais do seu tempo. As forças econômicas determinam as relações sociais e criam uma superestrutura jurídica e política que fomenta a reprodução de formas sociais determinadas. 0 Estado, nos dizem Marx e Engels (2005), no sistema capitalista, funciona como uma espécie de comitê administrativo dos interesses capitalistas da classe burguesa, que é a classe dominante.

Na perspectiva marxista, compreende-se que todo o aparato escolar funciona como aparelho ideológico e serve para reproduzir o sistema dominante ao nível ideológico, técnico e também produtivo. Atende, portanto, aos interesses da burguesia para a reprodução do modelo social por meio da formação de força de trabalho e de cidadãos coesos ao sistema a partir de valores introjetados na formação escolar. Porém, se esse processo de inculcação pode servir para reproduzir e legitimar o sistema capitalista, poderá servir, também, como 
via formadora da consciência revolucionária. Essa consciência individual é necessária à consciência de classe que pode mover a transformação e a superação da ordem hegemônica do capitalismo. A partir desse raciocínio, da possibilidade de formar a consciência emancipada que daria suporte a uma consciência socialista, movem-se os educadores que buscam nos escritos um modelo de educação alinhado e inspirado nas referências marxistas.

\section{A PEDAGOGIA HISTÓRICO-CRÍTICA, O SOCIALISMO COMO EXPECTATIUA SOCIAL E O DIÁLOGO COM O CENÁRIO PÓS- MODERNO}

Saviani se mantém fiel à prerrogativa marxista, não somente como perspectiva de leitura crítica da realidade social, mas como projeto revolucionário. Nesse sentido, é importante perguntar sobre o potencial educativo, para a realidade escolar deste tempo que vivemos, de uma pedagogia de orientação marxista (SAVIANI, 2010, 2011b, 2014, 2015, 2018a, 2018b). Saviani empenha-se em afirmar o potencial educativo de uma pedagogia que opere com sujeitos concretos, não previamente descritos pela abstração teórica, que resguarde as singularidades da vida prática, dos contextos, que leve em conta os modos peculiares como os sujeitos produzem o sentido da vida e a sua existência, certamente em modalidades muito mais complexas que algumas noções mais tradicionais conseguem alcançar, sejam elas de ordem psicológica, pedagógica, sejam políticas. Existe a necessidade, diz Saviani (2018a) com toda a pertinência, de que o debate pedagógico sobre a escola vá além dos "limites acanhados" dos slogans e soluções tecnocráticas, externas ao processo educativo em sua essência (a natureza política da formação) e, portanto, esvaziadas de conteúdo.

Dermeval Saviani afirma que pretendeu a elaboração de uma teoria pedagógica que permitisse "tornar o grupo social dos professores autônomo em relação a um ideário que ele havia acolhido sem crítica [tanto a Escola Tradicional, como a Escola Nova], esclarecendo as condições de produção e aplicação de uma nova teoria, a pedagogia histórico-crítica como alternativa superadora." (prefácio à $35^{\circ}$ edição de ED) (SAVIANI, 2002, grifo nosso).

0 esforço de Dermeval Saviani é o de salvar a pedagogia da essência como revolucionária, comprometida com a emancipação de toda a coletividade, pois opera com a ideia de um sujeito universal para poder justificar a defesa do conteúdo sem ser acusado de conservador. Esse conteúdo fica dignificado pelo novo fim que the é atribuído, uma ferramenta de emancipação a ser apropriada pelas classes populares. Esse posicionamento questiona a saída individualizante da pedagogia nova para sustentar o capital cultural como conteúdo revolucionário e motor da pedagogia histórico-crítica. 
Para isso, primeiro afirmou o caráter revolucionário da burguesia com a pedagogia tradicional, que usou da cultura para se afirmar socialmente perante uma sociedade baseada na tradição de nascimento. Em seguida, realocou a mesma pretensão revolucionária a serviço das classes populares. Permanece a cultura como veículo emancipatório.

A tentativa de síntese que pretende Saviani buscou conciliar uma pedagogia que estimule a atividade do aluno sem descuidar da iniciativa do professor, promovendo o diálogo dos alunos entre si, com o professor e também com a cultura, "sem perder de vista a organização lógica dos conhecimentos, sua ordenação e gradação para efeitos de sua transmissãoassimilação." (SAVIANI, 2003a, p. 69). Nessa perspectiva, o trabalho educacional desenvolvido na escola demandará que o professor seja capaz de compreender os vínculos de sua prática pedagógica com a prática social global, uma vez que dessa relação deriva a contribuição de cada um, com o seu conhecimento específico, para as finalidades sociais mais amplas.

A pretensão de formar as condições da transformação revolucionária que levaria ao socialismo mediante a formação desenvolvida na escola, situação em que finalmente se alcançaria a democracia real não se desenvolve, no cenário contemporâneo, sem ter que enfrentar as críticas e a própria crise do modelo socialista no mundo prático. 0 final dos anos de 1980 e o início dos anos de 1990 serviram de palco para a crise histórica do modelo socialista, de modo especial na Europa, com a desintegração da União Soviética, a queda do Muro de Berlim e a reunificação da Alemanha, além da queda de vários governos que estavam sob esta orientação ideológica no Leste Europeu. Nos anos posteriores, modelos de inspiração socialista, como o de Cuba e, mais recentemente, o da Venezuela, além das visíveis dificuldades econômicas, passaram a ser alvo de duras críticas e de denúncias de serem, na prática, sistemas autoritários e antidemocráticos mais do que promotores da igualdade social.

Saviani (2003a, 2017b, 2018b) reconhece e menciona esse contexto histórico. Compreende que a crise do socialismo ajudou a enfraquecer a influência marxista e a gerar um refluxo nas forças progressistas da educação. Aponta o avanço do que chamou de neoconservadorismo como sintoma desse recuo crítico e como a face da "onda" pósmoderna, mas pondera que não se pode dar como comprovada a inviabilidade do socialismo como solução global.

Com a hegemonia do mercado, "todos os problemas do mundo hoje são problemas do capitalismo." (SAVIANI, 2017b, p. 661). 0 autor destaca que o capitalismo se encontra em estágio de avançada crise, "impondo-se a exigência de sua transformação numa forma superior, de caráter socialista." (SAVIANI, 2018b, p. 82). Para ele, "em lugar de acreditar que o socialismo morreu e que Marx fracassou, estando definitivamente ultrapassado", há que se ver que "as evidências apontam em sentido contrário." (SAVIANI, 2017b, p. 661, grifo nosso). 0 autor entende como evidências de que o capitalismo vive uma crise global a prática de uma produção destrutiva em que somas de capital são investidas sem que as forças produtivas 
possam avançar além do nível já atingido, logo, o que se evidencia, a seu ver, é justamente uma "crise estrutural de caráter terminal" (SAVIANl, 2017b, p. 659-661, grifo nosso).

Marx e Engels (2005, p. 40) já haviam apontado que a história da humanidade é a história da luta de classes. 0 capitalismo, diz ele, vive crises estruturais que são cíclicas, geradas pelo excesso de produção e consequente redução nas margens de lucro, o que gera a necessidade de mais exploração da força de trabalho, redução nos salários para ampliar a margem de lucros, busca de novos mercados e exploração mais intensa dos antigos (MARX; ENGELS, 2005, p. 45).

Daí verifica-se que o capitalismo produz em si mesmo o gérmen de sua superação, via luta de classes, processo em que "tudo que é sólido se desmancha no ar [...] os homens são obrigados a encarar sem ilusões a sua posição social e as suas relações com outros homens." (MARX; ENGELS, 2005, p. 44).

A sua expectativa é a de continuar olhando de modo esperançoso para as possibilidades superadoras de sua pedagogia crítica, para a possibilidade de superação do modelo capitalista pelo socialismo e dialoga de modo tangencial com o cenário da pósmodernidade. Para ele, trata-se de uma radicalização das consequências econômicas do progresso capitalista e do consequente crescimento do estado de alienação política na sociedade. Para o autor, a pós-modernidade é um reflexo do neoconservadorismo, mas que não altera a força dos pressupostos da Modernidade sobre os quais se ampara teoricamente. Ele indica que boa parte das críticas "pós-modernas" já haviam sido pontuadas antecipadamente pelo próprio Marx. 0 autor aponta que Marx foi um crítico da metafísica, antes que isso virasse tema pelos pós-modernos, ao defender a materialidade da situação social e dos sujeitos nela situados. Aponta Marx como um crítico do idealismo, especialmente o hegeliano, ao optar por uma filosofia da práxis. Portanto, a seu ver, não estamos tratando de uma "concepção inserida nos limites do pensamento moderno." (SAVIANI, 2017b, p. 658).

Saviani indica, de forma salutar, que é preciso ler o contexto social contemporâneo para poder atuar sobre ele e continuar buscando a superação pelo resultado do trabalho escolar. Busca novamente em Marx o argumento para explicar o que está ocorrendo no cenário pós-moderno. Segundo o autor, o cenário atual está tomado pelo fetichismo da mercadoria já anunciado por Marx (1968, p. 79-93), fenômeno que ocorre quando o elemento material adquire elementos simbólicos valorativos que suplantam o valor objetivo e torna a sua aquisição uma necessidade.

A escola, nesse contexto, estaria hipertrofiada tanto vertical quanto horizontalmente. Enquanto expressão da modernidade, a escola lutou para difundir a ciência e superar todas as formas de obscurantismo. No entanto, no cenário pós-moderno, a escola passou a enfrentar toda forma de desvalorização, diz Saviani, sendo recolhida de suas 
funções vitais, deposta do lugar que havia ocupado na modernidade de ser "a forma" principal de educação. Outras formas de educação ganharam destaque, assim como outras formas de circular o conhecimento, material nobre com o qual se liga a escola em sua base moderna.

Vale lembrar que, enquanto no Brasil a teoria de fundo marxista inspirou as reflexões de cunho crítico no final dos anos de 1980 e seguintes, nessa mesma época, na Europa e nos Estados Unidos, emergiam as discussões que tratam sobre a entrada da pósmodernidade e de seus efeitos sobre a organização do campo das ideias, gerando outros referenciais teóricos. Obras como A condição pós-moderna, de Lyotard (1998), publicada originalmente em 1979, A filosofia e espelho da natureza, de Richard Rorty (1995), publicada também em 1979, e a espessa Teoria da ação comunicativa, de Jürgen Habermas (1987a, 1987b), publicada em 1981, representam um marco nas discussões teóricas que reconhecem o cenário contemporâneo como um terreno próprio de análise que não poderia ser examinado somente com aquilo que oferecia a teoria crítica disponível até o momento.

Parece-me que é preciso distensionar as expectativas com relação à tradição da dialética superadora, o que geraria uma necessidade de também revisar a própria didática da pedagogia formadora de novos intelectuais orgânicos como pretende Saviani. A complexidade do estágio atual do tecido social impõe novas exigências às práticas pedagógicas escolares e gera dificuldades renovadas para qualquer que seja a intencionalidade pedagógica.

Saviani (2010) entende que o movimento contemporâneo empobreceu as possibilidades transformadoras da escola. Isso ocorreu, segundo ele, diante do fato de que os valores do capitalismo transformaram a ideia de formação em capital humano individual como condição a uma melhor empregabilidade. Ele diz que esse "neoprodutivismo" estimula mais a competição, em uma sociedade de certificados e diplomas que são servidos por pedagogias que servem antes para a exclusão e culpabilização do indivíduo pelo seu eventual não êxito. 0 neoprodutivismo estaria complementado pelo avanço de duas faces pedagógicas: o "neoescolanovismo" e o "neoconstrutivismo", com o reaquecimento de um discurso de que importam mais os meios de aprender do que o conhecer em si, colocando na prática a ênfase na adaptabilidade dos sujeitos, mais do que na sua condição reflexiva, promovendo a redução do rigor científico e a emergência de uma retórica pedagógica que enfatiza o desenvolvimento de competências, a sobrevalorização do cotidiano em detrimento da cultura como um valor, mas, na verdade, gerando empobrecimento pedagógico da escola. 


\section{CRÍTICAS E OBJEÇÕES À PEDAGOGIA HISTÓRICO-CRÍTICA}

Saviani recebeu várias avaliações críticas sobre a sua obra. Em alguns momentos, ocupou-se com esse diálogo de modo a sinalizar os pontos em que considerava não ter sido compreendido adequadamente ou os pontos em que considerava que houve um equívoco de leitura das suas ideias. Em alguns casos pontuais, como na crítica que recebeu sobre ter feito uma avaliação depreciativa à Escola Nova, procedeu o ajuste da sua exposição para que pudesse ter as suas intenções melhor compreendidas. Em outros, ainda, optou por não entrar na discussão.

Nos aspectos mais abrangentes das críticas, o questionamento ao pouco valor que ele teria atribuído à Escola Nova é recorrente, assim como a indicação de que estaria defendendo a Escola Tradicional ao ressaltar com tanta ênfase a importância dos conteúdos como um valor em si no currículo escolar.

Nessa direção, destacam-se as críticas de Clarice Nunes (1991) e de Zaia Brandão (1992), em suas respectivas teses de doutorado. As autoras apontam que Saviani não teria feito um trabalho historiográfico suficiente para sustentar as críticas à Escola Nova que apresentou em Escola e Democracia. Zaia Brandão apontou, ainda, que um possível compromisso marxista excessivo que não teria the permitido reconhecer o processo da Escola Nova no Brasil como um movimento hibrido, em que constavam na sua defesa não somente nomes alinhados com o pensamento liberal, e cita como exemplo o caso de Paschoal Leme, mais alinhado com o pensamento de esquerda. Clarice Nunes, por sua vez, considerou que a análise de Saviani sobre a Escola Nova foi depreciativa e pouco justificada.

Com relação a essas críticas, Saviani argumenta que estava situado no âmbito do debate ideológico e não no plano da discussão historiográfica e, por isso, acentuou a polêmica ao forçar os argumentos contrários para poder confrontar o que considerava uma visão pedagógica não comprometida com a transformação social e que estava sendo amplamente defendida acriticamente pelos professores. Saviani (2010) retoma o que já tinha dito no prefácio à vigésima edição, publicada em 1988, e afirma que Escola e Democracia não é um livro que tem como objetivo ser contra a Escola Nova, já que no contexto do movimento escolanovista, marxistas e liberais estavam em torno de uma causa comum que era a melhoria da qualidade da escola brasileira, em particular, da escola pública.

Paulo Ghiraldelli, que foi orientando de Saviani em seu doutoramento, por diversas vezes teceu críticas e polemizou com o antigo mestre. Por ocasião do lançamento da obra História das ldeias Pedagógicas no Brasil (SAVIANI, 2007a), apontou que a orientação marxista de Saviani seria um limitador da sua leitura sobre o fenômeno educativo. A argumentação de Saviani teria recursividades e conclusões "pré-anunciadas". A causa disso, diz Ghiraldelli 
Júnior (2008, grifo do autor), "ainda é o seu marxismo", por estar habituado a ligar movimentos da economia e teses a respeito do trabalho e da sociedade como um todo ao aparecimento de determinadas concepções pedagógicas.

0 excessivo vínculo de Saviani com os "pressupostos marxistas" é também indicado em crítica feita por Joseane Machado Silva (2014). Segundo essa análise, por mais que Saviani utilize, em seus textos, autores não marxistas, "a concepção que ele tem de conhecimento" teria um efeito limitante em sua capacidade de análise, que gerariam sínteses renovadas, mais do que "análise aprofundada" (SILVA, 2014, p. 43).

No meio acadêmico de orientação marxista existem igualmente ponderações ao seu trabalho, seja com relação à apropriação de conceitos feitos por Saviani na obra de Marx, seja com relação à viabilidade de uma pedagogia socialista em um contexto socioeconômico em que prevalece o modelo capitalista.

Paulo Tumolo $(2005,2011)$ entrou no debate com Saviani, e também com Gaudêncio Frigotto, acerca da ideia do trabalho como princípio educativo a partir de Marx. Trata-se de uma discussão de verniz teórico-interpretativo para a apreensão das ideias de Marx e como elas são transportadas para a discussão educacional por cada um deles.

Em outro texto, Neide Favaro e Paulo Tumolo (2016, p. 566), trazem à discussão o mesmo raciocínio com questões que apontariam a compreensão equivocada da teoria marxista por parte de Saviani, em especial na fundamentação da Pedagogia Histórico-Crítica. Os autores mapeiam na obra de Saviani elementos que indicariam uma posição do autor na defesa de "um investimento privilegiado em educação, transformando-a em eixo central do desenvolvimento econômico", desse modo entendendo a educação como um bem de produção e não apenas um serviço ou bem de consumo. Para os autores há uma incompatibilidade entre defender essa ideia como para fomentar uma mudança em direção ao socialismo, servindo-se de uma lógica que mais favorece, no seu entender, a reprodução capitalista. A discussão vai adiante com outras questões e conceitos teóricos que transbordam o objetivo deste texto.

Por ocasião de uma pesquisa de doutoramento na Universidade Federal de Santa Catarina, desenvolvida por Ademir Lazarini (2010) e orientada por Paulo Tumolo, houve uma tentativa de desconstrução da leitura de Saviani sobre categorias do materialismo histórico aplicadas à educação. Segundo o autor, "Saviani se apropria de maneira problemática e/ou equivocada de algumas das principais categorias econômicas analisadas por Marx" (LAZARINI, 2010, p. 9) e, com isso, compromete "pela raiz as suas principais teses acerca da relação entre capital e educação formal", resultando em "incongruências" que, "no limite, entram em contradição com o projeto histórico socialista que o autor pretende defender." (LAZARINI, 2010, p. 35). Repete-se, nesse caso, a tese de que há equívocos na apropriação da obra de Marx por parte de Saviani. 
Saviani comentou que essas críticas não são uma novidade e, referindo-se pontualmente ao trabalho de Lazarini, entende que ele apenas sistematiza um conjunto de críticas já formuladas por outros autores nas décadas de 1980 e 1990, sem fazer avançar, resguardado o mérito de "reunir num só trabalho um conjunto de críticas formuladas de forma mais ou menos esparsa." (SAVIANI, 2013, p. 187). Em um texto sobre as controvérsias internas ao marxismo, Saviani (201la, p. 7) pondera que a análise crítica é inerente à tradição marxista, mas que "a crítica e o debate não devem gerar dificuldades para a unidade de propósitos", no caso, o projeto emancipatório e revolucionário.

Além de Lazarini (2010), outras teses de doutoramento orientadas por Tumolo (FAVARO, 2014; WIHBY, 2018) tomaram Saviani e aspectos de sua produção intelectual como tema. Favaro (2014) analisa o tipo de estratégia política adotada pela Pedagogia HistóricoCrítica para articular a defesa da escola pública com o projeto socialista. Toma, no caso, como eixo de discussão a articulação de Saviani no uso da teoria marxista na interface entre a ideia de revolução e de educação e aponta incongruências. Wihby (2018), por sua vez, propõe-se a fazer uma análise crítica do método de ensino da Pedagogia Histórico-Crítica. Ela contesta o que considera um equívoco de Saviani, ou seja, estabelecer uma correlação direta entre método de ensino e método de pesquisa, tratando de forma indiferenciada pesquisa, ensino e aprendizagem.

Parece que o núcleo da ideia de Tumolo, o de que Saviani comete equívocos no modo como se apropria da teoria marxista persiste também com seus orientandos. Esses equívocos no uso da matriz interpretativa gerariam contradições e aprisionamentos que deixariam Saviani em uma fronteira imprecisa quanto ao potencial revolucionário de sua pedagogia socialista.

Tonet (2016) levanta uma questão diversa: seria possível aplicar uma concepção socialista de educação no interior da sociedade capitalista? Embora não seja seu intento neste artigo polemizar com Saviani, Tonet menciona Saviani como um exemplo, e não apenas ele, de autores que se dispuseram a formular uma pedagogia de cunho socialista a partir do aporte teórico marxista. Para ele, uma pedagogia socialista seria necessariamente pública (estatal), gratuita, popular, laica, pautada no método experimental e científico tendo como foco a formação política e politécnica do proletariado.

Nessa perspectiva, portanto, entende de modo diverso de Saviani sobre a possibilidade de se aplicar uma "pedagogia socialista" sem as condições estruturais da sociedade terem sido modificadas. Defende que seria possível, sim, pensar em "atividades educativas" e não em uma "pedagogia socialista". Atividades educativas emancipadoras que contribuam para o avanço da luta revolucionária, já que a escola no capitalismo é um espaço em que as diferenças de classe estão presentes e visíveis. Tonet está alinhado com o pensamento de Saviani, mas diverge ao não considerar viável prescrever uma "pedagogia 
socialista" que possa ser efetiva em um ambiente capitalista. Prefere uma designação mais modesta, ao nominar como atividades educativas.

Saviani segue uma referência de diálogo teórico em toda a sua obra amparado pelos clássicos do marxismo. Ele é fiel à matriz teórica que o orienta e considera que ela preserva um potencial reflexivo atual, conforme ele mesmo indica no texto 0 legado de Karl Marx para a educação, publicado em 2018, em que o autor reafirma o potencial educativo de uma "pedagogia de orientação marxista" justamente, segundo ele, por ser "uma pedagogia concreta" que opera com os "educandos como indivíduos concretos" que são, que sintetizam relações sociais que não escolheram (SAVIANI, 2018b, p. 81-82).

\section{CONSIDERAÇÕES FINAIS}

A escola atual, e em particular a escola pública, está consumida em dificuldades para realizar as suas tarefas mais elementares a ela destinadas pela tradição pedagógica moderna. Diante de uma sociedade desigual, a educação ofereceria um patrimônio de elevado valor: os bens culturais conformariam uma espécie de capital, o capital cultural, que cumpriria essa função equalizadora das diferenças sociais, e isso faz particular sentido na defesa da educação pública quando se afere legitimidade ao saber como patrimônio reconstrutor do equilibrio social.

0 século XX terminou sobre o pantanoso terreno da desigualdade, da opressão, da desumanização, produzindo um certo ressentimento com a modernidade e com as promessas humanistas herdadas do lluminismo, chegando a gerar um movimento "contrailuminista”, expresso, por exemplo, na força intelectual de muitas análises pós-modernas. 0 século XXI avança marcado pela multiplicidade de discursos e por dificuldades práticas incontáveis nas realidades concretas das escolas, de modo especial na rede pública. 0 fato é que há muitos fatores que geraram o eclipse das certezas e lançaram a dúvida sobre a validade das promessas modernas. Esse estado de incredulidade, do qual falava Lyotard (1998), traduz um estado de espírito e um certo aborrecimento intelectual com perspectivas que lancem intentos superadores ou mesmo renovadores das promessas modernas.

Seja como for, há uma organizada contestação teórica e prática em campo sobre os elementos básicos que constituíram as promessas modernas. Vemos a denúncia de que a ideologia tem vestes de ciência e ares de tecnologia, mas, na verdade, tomou o lugar da religião e virou um novo mito a ser superado. Lembrando Adorno e Horkheimer (1985), a modernidade gerou uma razão que, instrumentalizada, danificou o sentido das práticas humanas, em particular, a partir de medidas geradas pela indústria cultural. Essa 
danificação de sentido, para Habermas, ocorre porque houve um desacoplamento do mundo da vida dos sujeitos diante da prevalência dos ditames instrumentais do mundo do sistema capitalista liberal.

Qual a viabilidade de enunciarmos no contexto contemporâneo um discurso para animar a educação nas escolas brasileiras considerando o complexo cenário social e educacional em que nos encontramos? Essa parece ser uma pergunta fundamental, ao mesmo tempo complexa e de difícil resposta. Talvez seja como o próprio cenário em que é gerada: promove um certo mal-estar pela impossibilidade de uma resposta definida lou mesmo definitiva) a despeito de todo avanço tecnológico ou teórico que a civilização possa ter alcançado. Não há como regular o futuro.

Dermeval Saviani destaca, em sua forma de pensar a educação, o sujeito de conhecimento. Ele está preocupado com o esvaziamento acadêmico que assolou a escola durante a década de 1970, e daí se compreende melhor a sua dura crítica aos processos pedagógicos que dão prioridade aos modos de aprender em detrimento do conhecimento a ser aprendido. Entende que isso enfraquece politicamente as classes populares, pois vê na cultura um patrimônio emancipatório fundamental.

Pode-se facilmente verificar que, nesse cenário pedagógico desenvolvido, encontram-se conceitos importantes e válidos para pensar a educação brasileira atual. 0 estímulo de processos de tomada de consciência e maior compreensão de si e da realidade, a perspectiva do sujeito de conhecimento e a perspectiva da escola pública como patrimônio para a promoção da democratização da sociedade, entre outras categorias já subsidiadas da modernidade, são recontextualizadas por Saviani no cenário brasileiro.

Parece razoável sinalizar que a apropriação dessa tradição brasileira pode oferecer suporte à reflexão pedagógica em um processo de reconstrução das premissas educacionais atuais. Convém, porém, recorrer ao alerta de não recairmos em um saudosismo nostálgico que nos faça esperar demais da tradição. Sempre há um apelo reacionário rondando essa perspectiva. Também convém lembrar que é necessário superar conceitos modernos como consciência de si, autodeterminação e autorrealização, próprios de uma razão centrada em uma ideia de sujeito hipertrofiada.

A proposta da Pedagogia Histórico-Crítica oferece recursos para pensar fundamentos para uma educação crítica. Tem o mérito de valorizar a cultura e o potencial do conhecimento como instrumento para a construção da crítica social e o fato, primordial, de pensar uma prática didática ancorada na realidade social, terreno gerador das problemáticas de trabalho e destino final das reflexões feitas a partir do seu esclarecimento.

Para Saviani, conhecer, problematizar e emancipar são ingredientes de um mesmo processo pedagógico que fará sentido na vida imediata ao retornar à prática social que o 
desencadeou como possibilidade de esclarecimento e de superação de seus limites. Saviani difere menos do que parece das propostas da Escola Nova em termos metodológicos. Está preocupado com uma noção compreensiva do conhecimento le nisso afasta-se da epistemologia da mera transmissão como tarefa da escola) e, sim, preocupa-se com os meios de aprender, pois sabe que o que chama de instrumentação do problema requer pesquisa, discussão e enfrentamento de novas questões não previstas. Resguarda o papel ativo do professor, mas não com o papel que lhe fora atribuído na Escola Tradicional, o do mestre explicador, como diria Ranciére..$^{10}$ É, antes, um mestre mediador, embora, para ele, a noção de mediação tenha um sentido bem específico e tem a ver com agir sobre o meio e transformá-lo, já que ele fala da mediação da análise (SAVIANI, 2015, 2017a), ou seja, trata-se de um processo compreensivo e não de uma atuação como propõe a Escola Nova ou as perspectivas construtivistas, herdeiras do escolanovismo.

Para Saviani (2015, 2017a), a mediação dá-se com a realidade e é um processo em que estão envolvidos, em patamares prévios distintos de condição compreensiva, e não o papel do professor em si, como ocorre na perspectiva da Escola Nova. Saviani postula algo diferente; pretende que o professor exerça um papel ativo na condução, com seus alunos, do processo de entendimento das relações teórico-práticas para equacionar as questões derivadas da prática social e que a ela devem retornar como possibilidade de ação, uma vez que esclarecidas e postas em um patamar superior de compreensão que modifique os padrões da consciência acerca dessa mesma prática social. Encontra-se nesse caminho de condição reflexiva para o potencial do conhecimento, que, para ele, só cumprirá a sua função se permitir atingir um patamar superior de consciência. E justamente essa consciência de nível superior, crítica, "capaz de compreender relações, compreender as determinações que se ocultam sob as aparências dos fenômenos que se manifestam empiricamente." (SAVIANI, 2015, p. 36).

A vida em sociedade vive uma lógica social perturbada, fragmentada, muito aos moldes do que Lyotard (1998) denominou como um verdadeiro estado de incredulidade ao falar sobre o pós-moderno. A lógica formal, as grandes narrativas ou explicações sistêmicas, o formalismo, o racionalismo cartesiano e outras tantas marcas da tradição da Modernidade se, por um lado, podem ter as suas pretensões de validade questionadas pela radical pluralidade contemporânea, por outro, não esgotam os seus conteúdos e a sua possibilidade de gerar recursos para interpretar as necessidades contemporâneas. Mas é possível que seja necessário atualizar as suas prerrogativas e a validade de seus argumentos para contextos distintos daqueles em que foram formuladas.

10 Menção à obra 0 Mestre lgnorante, de Jacques Ranciére, publicada pela Editora Autêntica. Nessa obra o autor conta a história do mestre Joseph Jocot, no século XIX, que busca superar a lógica tradicional contida na máxima do "mestre explicador." A verdadeira emancipação estaria na lógica que não subordina uma inteligência à outra como na forma tradicional. 0 mestre "ignorante" poderia ensinar o que não sabe sendo um mestre "indagador" que mostra um interesse pelo aprendizado movido pela curiosidade e desejo de saber e não pelas "explicações" do mestre (RANCIÉRE, 2010). 
Analisar a vida cotidiana a partir de categorias mais estáticas nem sempre é frutiffero. Nem sempre as explicações estruturais dão conta de mapear ou "enquadrar" o que emerge nas escolas no cenário contemporâneo. Muitas vezes, os determinantes da prática social geram toda sorte de dificuldades para o êxito de qualquer metodologia pedagógica, crítica ou não. Nem todo cenário social consegue ser abarcado pelo espectro das categorias de classe, mudança, revolução ou consciência, ainda que se possa dizer, sim, que o que a perturbação social e psicológica que vivemos neste início de século não é menos do que a decorrência das implicações de vivermos em um modelo de capitalismo excludente e predatório.

Esperar que as consciências transformadas e esclarecidas sejam capazes de formar um sentido coletivo que vá alterar a ordem social e por em causa o sistema econômico é um projeto ambicioso e o tempo histórico parece que já mostrou que as dificuldades práticas de sua viabilização passam por questões de ordem humana, em que se sobrepõe a vontade de poder dos sujeitos autoritários, assegurados da ideia de que sabem como a vida devia ser e que conhecem o caminho para atingi-la. Não há dúvida de que a democracia formal é um estágio importante, assim como é certo que não garante isonomia social, e as contradições persistem.

Seja como for, podemos desinflacionar um pouco as expectativas e dialogar com perspectivas que tenham alguma porosidade, menos idealismo e um certo sentido pragmático de ver o que dessa proposta nos ajuda a interpretar e encontrar soluções para a educação, talvez com expectativas mais modestas, embora para a perspectiva marxista, a superação do capitalismo pelo socialismo seja uma busca indiscutível e realizável, dado que o sistema capitalista estaria à beira do colapso.

Pensar que o projeto de emancipação humana está vinculado, obrigatoriamente, à superação do capitalismo pelo socialismo é um ideal (que pode ser posto à discussão), mas esse projeto, essencialmente moderno, pode nutrir as práticas pedagógicas talvez com expectativas mais modestas que proporcionem meios de maior entendimento da realidade imediata, embora sem garantias de que isso resultará em uma transformação social radical. Por outro lado, entregar-se ao "pós-moderno" no sentido que não há mais nenhuma expectativa de êxito seria sucumbir a uma espécie de nilismo pedagógico que daria cabo ao significado histórico da escola sob o qual ela foi construída, que é o cultivo da condição de autonomia crítica e da sensibilidade social.

Podemos levar em conta que o modo de compreender a recepção de uma teoria pedagógica está necessariamente entrelaçado com a cultura local do contexto que pretende receber essa teoria e que há um diálogo necessário com o contexto em que ela foi produzida, procedendo, ao modo de Saviani, um exercício crítico, portanto, reflexivo e coletivo. 
É preciso estar atento para reconstruir um discurso alertado de que não há mais hipotecas que garantam os resultados da formação oferecida aos sujeitos e não há também nenhum resgate assegurado de que essas promessas sejam justificáveis em todos os contextos. A busca de um acordo de convicções racionalmente motivado, menos esperançoso quanto a promessas de êxito e disposto ao contínuo debate argumentativo entre sujeitos capazes e dispostos ao diálogo pode oferecer uma possibilidade de que, reconhecida a heterogeneidade real dos contextos e pontos de vista, busque-se a intenção de Saviani, com honestidade intelectual e uma homogeneidade possivel, concreta, situada, mas não definitiva.

\section{REFERÊNCIAS}

ADORNO, T.; HORKHEMER, M. Dialética do Esclarecimento. Tradução: Guido Antonio de Almeida. Rio de Janeiro: Zahar, 1985.

AKSENEN, E. A Pedagogia Histórico-Crítica no bojo das Teorias Educacionais. Educere - Xll Congresso Nacional de Educação, Curitiba, 2015. Disponivel em: http://educere.bruc.com.br/arquivo/ pdf2015/17570_9258.pdf. Acesso em: 4 out. 2018.

BRANDÃO, Z. A Intelligentsia Educacional: um percurso com Paschoal Lemme por entre as memórias e as histórias da Escola Nova no Brasil. 1992. Tese (Doutorado em Educação) - Pontifícia Universidade Católica do Rio de Janeiro, Rio de Janeiro, 1992.

DEL ROI0, M. Gramsci e a emancipação do subalterno. Revista de Sociologia e Política, n. 29, p. 63-78, nov. 2007. DOl: http://dx.doi.org/10.1590/S0104-44782007000200006.

D0ZOL, M. Concepção histórico-crítica da educação: duas leituras. Perspectiva, Florianópolis, v. 12, n. 21, p. 105-118, 1994. D0l: https://doi.org/10.5007/\%25x.

FAVARO, N. 0 projeto político-estratégico da pedagogia histórico-crítica: uma análise das origens, do desenvolvimento, dos dilemas e da relação entre a escola pública e a luta socialista. 2014. Tese (Doutorado em Educação) - Universidade Federal de Santa Catarina, Florianópolis, 2014.

FAVARO, N.; TUMOLO, P. A relação entre educação e desenvolvimento econômico no capitalismo: elementos para um debate. Educação e Sociedade, Campinas, v. 37, n. 135, p. 557-571, abr./jun. 2016. D0l: 10.1590/ES0101-73302016149345.

FRIGOTTO, G. Dermeval Saviani e a centralidade ontológica do trabalho na formação do "homem novo", artífice da sociedade socialista. Interface, Botucatu, v. 21, n. 62, p. 509-519, maio 2017. D0l: http://dx.doi. org/10.1590/1807-57622016.0967.

GAMA, C.; SANTOS JÚNIOR, C. A contribuição de Dermeval Saviani no campo da Filosofia da Educação: reflexões acerca do currículo. Filosofia e Educação, Campinas, v. 8, n. 3, 2016, p. 57-80. D0l: https:// doi.org/10.20396/rfe.v8i3.8647087. 
GHIRALDELLI JÚNIOR, P. As ideias pedagógicas historiadas por Saviani. 2008. Disponivel em: http://ghiraldelliwordpress.com/2008/02/09/as-ideias-pedagogicas-historiadas-por-saviani/. Acesso em: 29 out. 2018.

GRAMSCI, A. Os intelectuais e a organização da cultura. Tradução: Carlos Nelson Coutinho. 5. ed. Rio de Janeiro: Civilização Brasileira, 1985.

HABERMAS, J. Teoria de la acción comunicativa. Critica de La razón funcionalista. Trad. Manuel Jiménez Redondo. Tomo II. Madrid: Taurus, 1987a.

HABERMAS, J. Teoria de la acción comunicativa. Racionalidad de La acción y racionalización social. Tradução: Manuel Jiménez Redondo. Tomo I. Madrid: Taurus, 1987b.

LAZARINI, A. A relação entre capital e educação escolar na obra de Dermeval Saviani: apontamentos críticos. 2010. Tese (Doutorado em Educação) - Universidade Federal de Santa Catarina, Florianópolis, 2010.

LIMA, J. F. L. A educação, o cenário da pós-modernidade e a questão da normatividade do discurso pedagógico. 2009. Tese (Doutorado em Educação) - Universidade Federal Fluminense, Niterói, 2009.

LYOTARD, J. A condição pós-moderna. Tradução: Ricardo Corrêa Barbosa. 5. ed. Rio de Janeiro: José Olympio, 1998.

MARX, K. Contribuição à crítica da economia política. Tradução: Florestan Fernandes. 2. ed. São Paulo: Expressão Popular, 2008.

MARX, K. 0 Capital. Tradução: Reginaldo Sant'anna. Rio de Janeiro: Civilização Brasileira, 1968.

MARX, K.; ENGELS, F. Manifesto comunista. Tradução: Alvaro Pina. 4. reimp. São Paulo: Boitempo, 2005.

NUNES, C. Anísio Teixeira: a poesia da ação. Tese (Doutorado em Educação) - Pontifícia Universidade Católica do Rio de Janeiro, Rio de Janeiro, 1991.

RANCIÉRE, J. 0 mestre ignorante: cinco lições sobre emancipação intelectual. Tradução: Lilian do Valle. Belo Horizonte: Autêntica, 2010.

RORTY, R. A filosofia e o espelho da natureza. Tradução: Antônio Trânsito. Rio de Janeiro: Relume Dumará, 1995.

SAVIANI, D. Da inspiração à formulação da Pedagogia Histórico-Crítica (PHC). Os três momentos da PHC que toda teoria verdadeiramente crítica deve conter. Interface, Botucatu, v. 21, n. 63, out./dez. 2017a, p. 711-725. D0l: http://dx.doi.org/10.1590/1807-57622017.0001. 
SAVIANI, D. A Pedagogia Histórico-Crítica. Revista Binacional Brasil Argentina, Vitória da Conquista, v. 3, n. 2. p. 11-36, dez. 2014.

SAVIANI, D. Ciência e educação na sociedade contemporânea: desafios a partir da pedagogia histórico-crítica. Revista Faz Ciência, Francisco Beltrão, v. 12, n. 16, p. 13-36, jul./dez. 2010.

SAVIANI, D. Debate sobre as relações entre educação, formação humana e ontologia a partir do método dialético. Perspectiva, Florianópolis, v. 31 n. 1, 185-209, jan./abr. 2013. D0l: https://doi. org/10.5007/2175-795X.2013v3ln1p185.

SAVIANI, D. Democracia, educação e emancipação humana: desafios do atual momento brasileiro. Psicologia Escolar e Educacional, v. 21, n. 3, p. 653-662, set./dez. 2017b. D0l: http://dx.doi. org/10.1590/2175-353920170213000.

SAVIANI, D. Escola e Democracia. 35. ed. Campinas: Autores Associados, 2002.

SAVIANI, D. Escola e Democracia. 36. ed. Campinas: Autores Associados, 2003a.

SAVIANI, D. Escola e Democracia. 42. ed. Campinas: Autores Associados, 2012.

SAVIANI, D. Escola e Democracia. 43. ed. Campinas: Autores Associados, 2018a.

SAVIANI, D. História das idéias pedagógicas no Brasil. Campinas: Autores Associados, $2007 a$.

SAVIANI, D. História, trabalho e educação. Comentários sobre as controvérsias internas ao campo do marxismo. Germinal: Marxismo e Educação em Debate, Londrina, v. 3, n. 2, p. 4-14 dez. 2011a. D0l: http://dx.doi.org/10.9771/gmed.v3i2.9448.

SAVIANI, D. Marxismo e Pedagogia. Revista HISTEDBR, Campinas, p. 16-27, abr. 2011b. Edição especial. D0l: https://doi.org/10.20396/rho.v1li4le.8639892.

SAVIANI, D. 0 conceito dialético de mediação na pedagogia histórico-crítica em intermediação com a psicologia histórico-cultural. Germinal: Marxismo e Educação em Debate, Salvador, v. 7, n. 1, p. 26-43, jun. 2015. D0l: http://dx.doi.org/10.9771/gmed.v7il.12463.

SAVIANI, D. 0 legado de Marx para a educação. Germinal: Marxismo e Educação em Debate, Salvador, v. 10, n. 1, p. 72-83, maio 2018b. D01: http://dx.doi.org/10.9771/gmed.v10i1.26557.

SAVIANI, D. Pedagogias contra-hegemônicas no Brasil. Ideação - Revista do Centro de Educação e Letras, Foz do Iguaçu, v. 10, n. 2, p. 11-28, 2008.

SAVIANI, D. Pedagogia histórico-crítica: primeiras aproximações. 8. ed. Campinas: Autores Associados, 2003b. 
SAVIANI, D. Trabalho e educação: fundamentos ontológicos e históricos. Revista Brasileira de Educação, v. 12, n. 34, p. 152-180, jan./abr. 2007c. D0l: http://dx.doi.org/10.1590/S1413-24782007000100012.

SEMERARO, G. Intelectuais orgânicos em tempos de pós-modernidade. Cadernos Cedes, v. 26, n. 70, p. 373-391, set./dez. 2006. D0l: http://dx.doi.org/10.1590/S0101-32622006000300006.

SILVA, J. Dermeval Saviani e sua "História das Ideias Pedagógicas no Brasil": em busca da compreensão de um autor e de uma obra. Revista HISTEDBR, Campinas, n. 57, p. 32-50, jun. 2014. D0l: http:// dx.doi.org/10.20396/rho.v14i57.8640402.

TONET, I. Marxismo, educação e pedagogia socialista. Germinal: Marxismo e Educação em Debate, Salvador, v. 8, n. 1, p. 37-46, jun. 2016. D0l: http://dx.doi.org/10.9771/gmed.v8i1.16978.

TUMOLO, P. S. 0 trabalho na forma social do capital e o trabalho como princípio educativo: uma articulação possível? Educação \& Sociedade, Campinas, v. 26, n. 90, p. 239-265, 2005. D0l: http://dx.doi. org/10.1590/S0101-73302005000100011.

TUMOLO, P. S. Trabalho, educação e perspectiva histórica da classe trabalhadora: continuando o debate. Revista Brasileira de Educação, v. 16, p. 443-482, 2011. D0l: http://dx.doi.org/10.1590/S141324782011000200010.

WIHBY, A. 0 método de ensino da pedagogia histórico-crítica: uma análise crítica. Tese (Doutorado em Educação) - Universidade Federal de Santa Catarina, Florianópolis, 2018.

Endereços para correspondência: Rua Alfredo Allen, 4200/135, Porto, Portugal; jfrancisco.lima@gmail.com 
